\title{
REVIEW
}

\section{Clinical review: Acute respiratory distress syndrome - clinical ventilator management and adjunct therapy}

\author{
Jonathan A Silversides ${ }^{1}$ and Niall D Ferguson ${ }^{* 1,2}$
}

\begin{abstract}
Acute respiratory distress syndrome (ARDS) is a potentially devastating form of acute inflammatory lung injury with a high short-term mortality rate and significant long-term consequences among survivors. Supportive care, principally with mechanical ventilation, remains the cornerstone of therapy although the goals of this support have changed in recent years - from maintaining normal physiological parameters to avoiding ventilator-induced lung injury while providing adequate gas exchange. In this article we discuss the current evidence base for ventilatory support and adjunctive therapies in patients with ARDS. Key components of such a strategy include avoiding lung overdistension by limiting tidal volumes and airway pressures, and the use of positive endexpiratory pressure with or without lung recruitment manoeuvres in patients with severe ARDS. Adjunctive therapies discussed include pharmacologic techniques (for example, vasodilators, diuretics, neuromuscular blockade) and nonpharmacologic techniques (for example, prone position, alternative modes of ventilation).
\end{abstract}

\section{Introduction}

Acute respiratory distress syndrome (ARDS) was first described in 1967 [1], and represents a common clinical problem in ICU patients. The syndrome is associated with a short-term mortality of approximately $45 \%$ [2] as well as significant long-term morbidity [3]. Despite being both a major clinical problem and a focus of research for

\footnotetext{
*Correspondence: n.ferguson@utoronto.ca

${ }^{2}$ Department of Medicine, Division of Respirology, University Health Network and Mount Sinai Hospital, University of Toronto, Mount Sinai Hospital, 600 University Avenue, Suite 18-206, Toronto, ON, Canada M5G 1X5

Full list of author information is available at the end of the article
}

the critical care community, ARDS remains difficult to define and a source of considerable controversy [4-7].

Using the 1994 American-European consensus criteria, ARDS was defined by widespread pulmonary infiltrates on chest radiograph, hypoxaemia, and the absence of elevated pulmonary capillary wedge pressure or other evidence of left atrial hypertension [8]. The new Berlin Definition of ARDS categorises ARDS as mild, moderate or severe, and was designed to address a number of issues that had become apparent with the previous definition (Table 1) [9].

ARDS represents a complex response to local and systemic inflammatory factors. Regardless of the underlying insult, the pathophysiological correlate of ARDS diffuse alveolar damage - involves neutrophil activation and endothelial injury, leading to noncardiogenic pulmonary oedema and atelectasis [10]. Studies using computed tomography have demonstrated that, in contrast to chest radiograph appearances, the distribution of disease is heterogeneous with atelectatic-dependent regions and relatively well-aerated 'baby lungs' in nondependent areas $[11,12]$. Recognition of the heterogeneity of disease distribution has led to the concept of recruitable lung regions and the need to deliver lower than historical tidal volumes to avoid overdistension of the baby lung.

The main differential diagnoses for ARDS are cardiogenic pulmonary oedema, atypical infections, and diseases such as cryptogenic organising pneumonia, acute eosinophilic pneumonia, and acute interstitial pneumonitis. While mimicking conditions such as cryptogenic organising pneumonia may produce an indistinguishable clinical picture, they are much less common than ARDS. [9] An important point to recognise is that ARDS is a clinical syndrome with heterogeneous underlying pathological processes rather than a discrete diagnostic entity. Conditions associated with the onset of ARDS are diverse and are often classified as extrapulmonary (examples include sepsis, trauma, burns and pancreatitis) or pulmonary, such as pneumonia, pulmonary contusion or aspiration of gastric contents. Addressing the underlying condition in a timely fashion is essential - for example, with 
Table 1. Berlin Definition of acute respiratory distress syndrome

\begin{tabular}{|c|c|}
\hline Timing & Within 1 week of a known clinical insult or new/worsening respiratory symptoms \\
\hline Chest imaging ${ }^{\mathrm{a}}$ & Bilateral opacities - not fully explained by effusions, lobar/lung collapse, or nodules \\
\hline Origin of oedema & $\begin{array}{l}\text { Respiratory failure not fully explained by cardiac failure or fluid overload; need objective assessment (for example, } \\
\text { echocardiography) to exclude hydrostatic oedema if no risk factor present }\end{array}$ \\
\hline \multicolumn{2}{|l|}{ Oxygenation ${ }^{b}$} \\
\hline Mild & $200<\mathrm{PaO}_{2} / \mathrm{FiO}_{2} \leq 300$, with PEEP or CPAP $\geq 5 \mathrm{cmH}_{2} \mathrm{O}^{c}$ \\
\hline Moderate & $100<\mathrm{PaO}_{2} / \mathrm{FiO}_{2} \leq 200$, with PEEP $\geq 5 \mathrm{cmH}_{2} \mathrm{O}$ \\
\hline Severe & $\mathrm{PaO}_{2} / \mathrm{FiO} 2 \leq 100$, with PEEP $\geq 5 \mathrm{cmH}_{2} \mathrm{O}$ \\
\hline
\end{tabular}

CPAP, continuous positive airway pressure; $\mathrm{FiO}_{2}$, fraction of inspired oxygen; $\mathrm{PaO}_{2}$, partial pressure of arterial oxygen; $\mathrm{PEEP}$, positive end-expiratory pressure. ${ }^{\mathrm{a}} \mathrm{Chest}$ $\mathrm{X}$-ray or computed tomography scan. 'blf altitude higher $>1,000 \mathrm{~m}$, correction factor should be made as follows: $\mathrm{PaO}_{2} / \mathrm{FiO}_{2} \times($ barometric pressure $/ 760$ ). This may be delivered non-invasively in the mild acute respiratory distress syndrome group. Adapted with permission from [9].

antibiotics and source control for sepsis - in addition to the provision of supportive care.

The majority of patients with ARDS will require invasive mechanical ventilation, although the successful use of non-invasive ventilation has also been described [13]. ARDS may resolve with supportive treatment, heal with interstitial fibrosis, or contribute to systemic inflammation and death. We review current evidencebased practices for invasive ventilation and discuss adjunctive therapies for ARDS.

\section{Clinical ventilator management Goals of mechanical ventilation}

The goals of mechanical ventilation for ARDS are to minimise iatrogenic lung injury while providing acceptable oxygenation and carbon dioxide clearance.

While the contribution of ventilator-induced lung injury (VILI) to ARDS has not been fully elucidated, it is clear from animal models that mechanical ventilation can cause pathologic changes consistent with ARDS in the absence of other insults [14]. Mechanisms of VILI include alveolar overdistension (volutrauma), repetitive alveolar opening and closure (atelectrauma), oxygen toxicity, and biotrauma, the pulmonary and systemic response to alveolar overdistension that may exacerbate lung inflammation and contribute to multiple organ dysfunction $[15,16]$. Efforts to minimise VILI are focused on the use of low tidal volume ventilation to prevent volutrauma, the use of positive end-expiratory pressure (PEEP) to reduce alveolar collapse, and minimisation of exposure to potentially harmful oxygen concentrations. Specific therapies targeted at the immune response remain experimental to date.

Acceptable parameters for the partial pressure of arterial oxygen $\left(\mathrm{PaO}_{2}\right)$ and the partial pressure of arterial carbon dioxide are difficult to define. Although $\mathrm{PaO}_{2}$ of 55 to $80 \mathrm{mmHg}$ is considered the target range in many studies, more profound hypoxaemia may be well tolerated, as evidenced by the relatively rare occurrence of death due to refractory hypoxaemia in ARDS [17], the occurrence of well-tolerated profound hypoxaemia (average of $24.6 \mathrm{mmHg}$ or $3.28 \mathrm{kPa}$ ) in climbers on Everest [18], and the reported survival of patients with ARDS and $\mathrm{PaO}_{2}<30 \mathrm{mmHg}$ (4 kPa) [19]. However, caution should be exercised in view of the reported correlation between cognitive defects in survivors of ARDS and duration of arterial oxygen saturation $<90 \%$ [20].

Inhalation of high concentrations of oxygen (fraction of inspired oxygen $\left(\mathrm{FiO}_{2}\right) \geq 0.8$ ) is associated with progressive alveolar damage and death in animal studies [21]. In healthy human volunteers exposed to high concentrations of oxygen, tracheobronchitis develops after several hours [22] and prolonged exposure is associated with decreased vital capacity [23], increased dead space, increased production of reactive oxygen species, and biochemical markers of alveolar-capillary leak [24]. In a small series of patients with ARDS, ventilation with $100 \%$ oxygen was associated with increased intrapulmonary shunt, attributed to nitrogen reabsorption and atelectasis [25]. Compared with other aspects of VILI, however, relatively little work has been done on oxygen toxicity in adults with ARDS, and the threshold for toxicity, particularly in the setting of an open lung strategy and low tidal volume ventilation, is unknown. Based on the limited available data, our practice is to aim for $\mathrm{FiO}_{2} \leq 0.6$ and to consider adjunctive therapies where this cannot be achieved by recruitment manoeuvres and higher PEEP alone.

Since low tidal volumes are protective despite resulting in higher partial pressure of arterial carbon dioxide levels [26], there has been increasing acceptance of hypercapnia as being harmless or even potentially beneficial by virtue of rightward shift of the oxyhaemoglobin dissociation curve, systemic and microcirculatory vasodilatation, and inhibitory effects on neutrophils and other inflammatory cells [27]. The optimal partial pressure of arterial carbon dioxide level for patients with ARDS is not clear, but mean levels of $66.5 \mathrm{mmHg}$ $(8.87 \mathrm{kPa})$ and $\mathrm{pH} 7.23$ appear safe [28,29] in the absence of a clear contraindication to hypercapnia, such as raised intracranial pressure. 


\section{Ventilation}

Following numerous animal and observational human studies, the landmark ARDS Network study provided clear evidence of large mortality benefit when patients with ARDS were ventilated with a lung-protective strategy aimed at avoidance of alveolar overdistension using tidal volumes of $6 \mathrm{ml} / \mathrm{kg}$ predicted body weight (Box 1) with plateau pressures $\leq 30 \mathrm{cmH}_{2} \mathrm{O}$ [26]. Adjustment of the ventilator rate was used to target a normal $\mathrm{pH}$, with a mean respiratory rate of 30 breaths/minute in the low tidal volume arm. Tidal volumes in patients with ARDS should therefore be in the order of $6 \mathrm{ml} / \mathrm{kg}$ predicted body weight with plateau pressures $<30 \mathrm{cmH}_{2} \mathrm{O}$, accepting $\mathrm{pH}$ as low as 7.15 to achieve these targets.

Many ventilation modes have been employed in ARDS. To add to the confusion, manufacturers often use different names for similar modes. One must choose between spontaneous breathing modes with partial ventilatory support, or controlled modes; either a pressurecontrolled mode in which tidal volume is the dependent variable, or a volume-controlled mode in which peak pressure may vary.

Spontaneous breathing with partial ventilatory support has been postulated to allow for better patient-ventilator synchrony, lower sedation requirements, and better preservation of diaphragmatic function with earlier liberation from mechanical ventilation. Data supporting this hypothesis, however, are currently very limited. A recent systematic review [30] identified only two small randomised controlled trials (RCTs) addressing this question, both of which used airway pressure release ventilation as the spontaneous breathing mode. One of these trials suggested improved oxygenation and increased number of ventilator-free days [31], but concerns exist that these may have been driven largely by decrements in the control group; meanwhile, the other trial showed no effect on clinical outcomes [32]. The main disadvantage of spontaneous breathing is the potential for the patient to generate high transpulmonary pressures and tidal volumes; suppression of this often requires the use of high doses of sedation with or without muscle relaxants. Balancing the risks between increasing sedation in order to provide lung protection and allowing spontaneous ventilation in a more awake patient is often a difficult clinical problem with limited applicable evidence. Our practice is to aim for spontaneous breathing with partial ventilatory support, frequently using pressure support ventilation in patients with mild to moderate ARDS, while in moderate to severe ARDS patients we use sedation and muscle relaxants as necessary to achieve lung-protective ventilation.

Proponents of pressure-controlled ventilation argue that this allows for better patient-ventilator synchrony, that the decelerating flow pattern allows better

\section{Box 1. Calculation of predicted body weight}

$50+0.91(\mathrm{~cm}$ of height -152.4 ) for males

$45.5+0.91$ ( $\mathrm{cm}$ of height -152.4$)$ for females

distribution of inspired gases, and that high transpulmonary pressures are more easily avoided [33]. Conversely, volume-controlled ventilation allows safe tidal volumes to be delivered in a consistent pattern, thus avoiding alveolar overdistension [34]. Pressure-regulated volume control ventilation aims to combine the advantages of both approaches, but may be problematic when patients are making variable or intermittent inspiratory efforts. There is no evidence of benefit for any one mode, the important point being to ensure both safe tidal volumes $(6 \mathrm{ml} / \mathrm{kg}$ predicted body weight) and plateau pressures $\left(\leq 30 \mathrm{cmH}_{2} \mathrm{O}\right)$ regardless of the mode used.

Various less conventional modes (for example, proportional assist ventilation, neurally adjusted ventilatory assist, and so forth) have so far not been demonstrated to offer significant benefits over conventional modes of ventilation in ARDS.

Alveolar recruitment and positive end-expiratory pressure Higher levels of PEEP with or without recruitment manoeuvres are often used to improve oxygenation. Using a transient increase in transpulmonary pressure, recruitment manoeuvres attempt to open previously atelectatic alveoli. This increase in the size of the ARDS baby lung [12] allows distribution of inspired gas among greater numbers of lung units, leading to less overdistension of individual alveoli and potentially less VILI [35]. Several methods have been described, the most commonly used of which is a sustained inflation breath; for example, $40 \mathrm{cmH}_{2} \mathrm{O}$ for 40 seconds [35]. Another manoeuvre that appears to be gaining popularity is a step-wise increase in PEEP accompanied by low levels of pressure control ventilation [36,37]. Common complications of any recruitment manoeuvre include transient hypotension and desaturation, while pneumothorax and other manifestations of barotrauma have been reported and transient alveolar overdistension during the manoeuvre may paradoxically worsen VILI [35]. Recruitment manoeuvres are associated with an immediate improvement in oxygenation with variable sustainability, but have not been shown to improve clinically important outcomes $[38,39]$. They may be most useful as a rescue therapy in refractory hypoxaemia or following deterioration in oxygenation attributable to worsening atelectasis.

The sustainability of improvements in oxygenation with recruitment manoeuvres may depend on the use of PEEP as a means of maintaining recruitment. In selecting a 
PEEP level, one must consider both the target level (low, moderate, high) and the method for determining the actual numeric value of PEEP. In terms of target level, there is at least observational evidence to suggest that very low levels of PEEP $\left(<5 \mathrm{cmH}_{2} \mathrm{O}\right)$ are associated with worse mortality [40]. The debate regarding targets of moderate versus higher levels of PEEP is informed by three recent large RCTs that maintained low tidal volumes in all patients [41-43]. While none of these trials individually showed a significant mortality benefit, when combined in an individual-patient meta-analysis the patients with moderate-severe ARDS $\left(\mathrm{PaO}_{2} / \mathrm{FiO}_{2} \leq 200\right)$ had lower mortality and more ventilator-free days with higher levels of PEEP (approximately $15 \mathrm{cmH}_{2} \mathrm{O}$ on day 1) [44]. In contrast, patients with mild ARDS $\left(\mathrm{PaO}_{2} / \mathrm{FiO}_{2}=\right.$ 201 to 300) showed a nonsignificant trend towards worse outcomes with higher PEEP; no benefit was seen in the overall population (see Figure 1) [44].

In terms of determining the exact level of PEEP for an individual patient within a targeted approach, several methods have been described. These methods most commonly consist of using a $\mathrm{PEEP} / \mathrm{FiO}_{2}$ table in which PEEP is titrated to provide acceptable oxygenation $[26,41,42]$, titrating PEEP to a maximal acceptable plateau pressure while maintaining a safe tidal volume [43], or a decremental PEEP approach where a recruitment manoeuvre is followed by titration of PEEP to the minimum required to prevent de-recruitment and atelectrauma [45]. This decremental approach is most easily achieved by a sustained inflation breath or pressure control recruitment manoeuvre, followed by a decremental reduction in PEEP until a deterioration in compliance or oxygenation occurs, followed by a further recruitment manoeuvre and setting the PEEP $2 \mathrm{cmH}_{2} \mathrm{O}$ above this point [35]. This method of identifying a point of derecruitment correlates well with that found on serial computed tomography imaging [46]. Similar results may be obtained regardless of the specific target used as a marker of lung opening [47].

An intriguing recent report describes setting PEEP guided by oesophageal pressures as a surrogate for pleural pressure [48]. Transpulmonary pressure is then calculated and the PEEP set to achieve a positive endexpiratory transpulmonary pressure, with higher pressures used for higher $\mathrm{FiO}_{2}$ requirements. In a small singlecentre RCT this approach led to improvements in oxygenation and even a suggestion of improved mortality [48]. Given the complexities involved in measuring and standardising oesophageal pressure measurements, and the preliminary nature of these findings, we believe that confirmation in the form of a larger multicentre RCT is required before this approach is used in the majority of ARDS patients. Other experimental methods of setting PEEP include titration to the minimum dead space fraction [49], optimal cardiac output, or transcutaneous oxygen tension [50], although none of these methods appears widely used in current clinical practice.

Our pragmatic approach is to use the lower ARDS Network PEEP $/ \mathrm{FiO}_{2}$ tables as a guide in most mechanically ventilated patients [26], with adjustment according to clinical response and our impression of chest wall compliance (obesity, oedema, or intra-abdominal hypertension may imply the need for higher PEEP to prevent gravitational alveolar collapse). In patients with moderate ARDS $\left(\mathrm{PaO}_{2} / \mathrm{FiO}_{2}=101\right.$ to 200$)$ we typically switch to a higher $\mathrm{PEEP} / \mathrm{FiO}_{2}$ table $[41,42]$, and if oxygenation remains problematic in severe ARDS $\left(\mathrm{PaO}_{2} / \mathrm{FiO}_{2}<100\right)$ we often use recruitment manoeuvres followed by a decremental PEEP trial.

The inspiratory:expiratory ratio is generally set at a ratio of 1:2 as a default, but may be increased to $1: 1$ as needed in order to increase the mean alveolar pressure, to allow more time for filling of lung units with long time constants, and to increase alveolar recruitment. The main risk from this ratio increase is gas trapping, and therefore monitoring of the flow-time curve to ensure nearcessation of flow prior to inhalation is essential. Inverse ratio ventilation, with inspiratory:expiratory ratio $>1: 1$, results in higher mean airway pressures and can improve oxygenation but appears less useful than increasing PEEP - and the associated intrinsic PEEP may worsen gas exchange, volutrauma, and haemodynamics $[51,52]$.

\section{Pharmacological adjuncts \\ Pulmonary vasodilators}

Inhaled nitric oxide is a potent but extremely shortacting pulmonary vasodilator that selectively improves perfusion to well-ventilated alveoli, reducing intrapulmonary shunt and improving oxygenation. Despite improvements in oxygenation, the use of inhaled nitric oxide is not associated with any mortality benefit, is expensive, and requires a specialist delivery system [53,54]. A recent systematic review found a suggestion of increased renal failure in association with its use, although biologically plausible explanations for this remain speculative [53]. Our practice is to use inhaled nitric oxide in ARDS as rescue therapy for reversible, life-threatening hypoxaemia, usually as a starting dose of $5 \mathrm{ppm}$ and titrating to a maximum of $20 \mathrm{ppm}$, with discontinuation if no significant improvement in oxygenation is apparent after a short trial.

Inhaled prostacyclin has similar theoretical benefits to nitric oxide in terms of selective pulmonary vasodilatation, but has been less extensively studied in the context of ARDS [55]. Small physiological studies suggest an equivalent effect on pulmonary artery pressures and oxygenation to inhaled nitric oxide, although none have been powered to compare clinically important endpoints 
In-hospital time to death

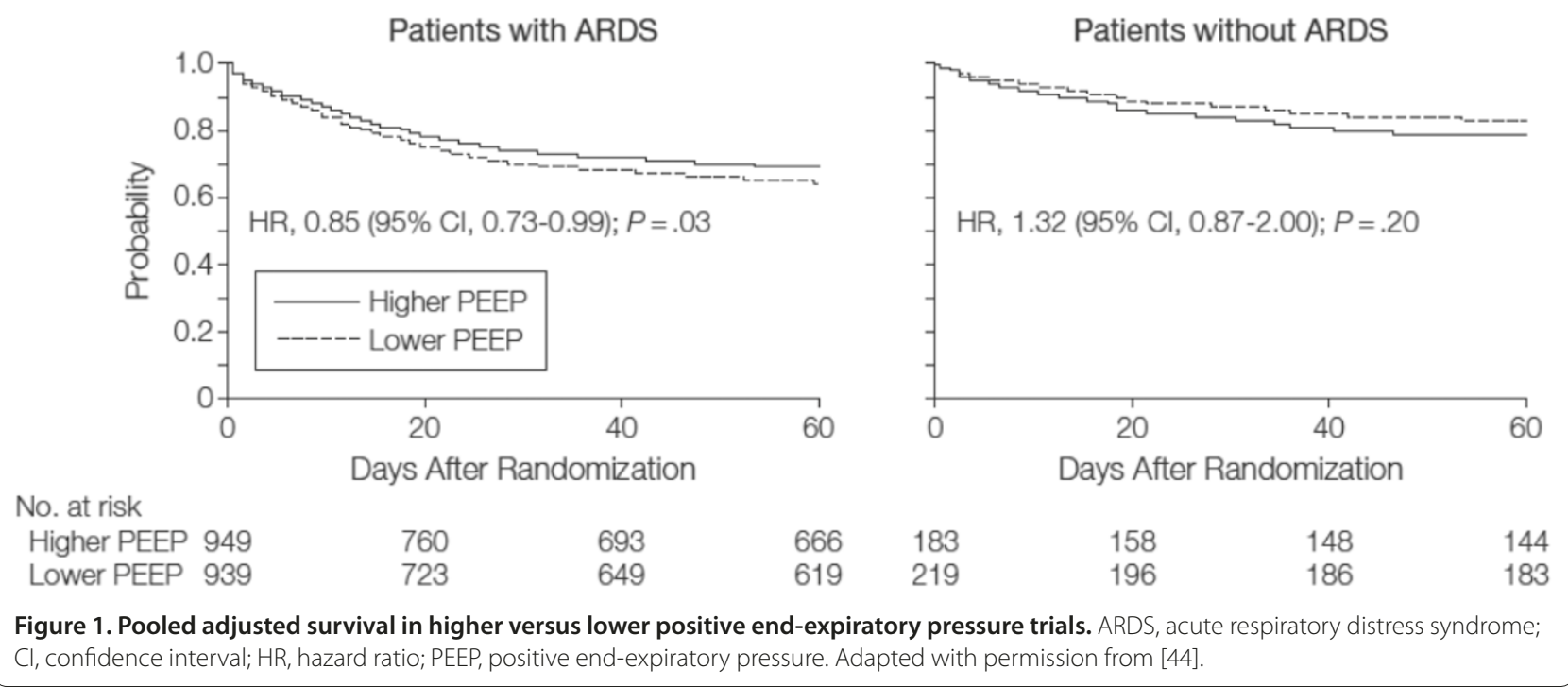

$[55,56]$. Evidence for prostacyclin use is confined to these small studies and case reports. The clinical relevance of theoretical side effects such as systemic vasodilatation and platelet dysfunction is unknown. Prostacyclin is considerably less expensive and does not require the same commercial delivery system as nitric oxide, but the nebuliser requires continual observation during prostacyclin delivery, and the technique remains an unproven rescue therapy for life-threatening hypoxaemia.

\section{Fluid balance}

The three factors involved in oedema formation are hydrostatic pressure, colloid osmotic pressure, and the capillary filtration coefficient. In the absence of effective methods to reduce pulmonary capillary leak (that is, the filtration coefficient), efforts to reduce extravascular lung water in ARDS are centred on minimising hydrostatic pressure by avoiding fluid overload, and potentially the use of albumin solutions to increase colloid osmotic pressure.

An association between positive fluid balance and worse outcome in patients with ARDS has been demonstrated in a number of studies $[57,58]$. Data from the ARDS Network Fluids and Catheter Therapy Trial support the use of a conservative fluid management strategy in ARDS, with the use of diuretics in haemodynamically stable patients to achieve an even fluid balance associated with improved oxygenation and faster liberation from mechanical ventilation [59]. While a dry approach to patients with sepsis and particularly ARDS has traditionally been assumed to benefit lungs at the expense of renal and other organ perfusion, a growing body of evidence exists to the contrary. In ARDS patients enrolled in the Fluids and Catheter Therapy Trial, for instance, conservative fluid management was associated with lower rates of acute kidney injury in ARDS patients once correction for changes in the volume of distribution of creatinine was used [60]. These findings of acute improvements from the Fluids and Catheter Therapy Trial need to be interpreted in light of a recent report showing potential for worse long-term cognitive function in a subset of the trial survivors [61].

In general, unnecessary fluid administration should be minimised using small-volume fluid boluses titrated to resolution of hypoperfusion states. Diuretics or ultrafiltration should be employed to restore euvolaemia in haemodynamically stable patients who have received fluid loading in the resuscitation phase of their illness. However, in some patients, particularly those with severe ARDS requiring high mean airway pressures for oxygenation, hypovolaemia may exacerbate hypoxaemia by virtue of increased intrapulmonary shunt, and clinical benefit may result from the careful administration of fluid boluses.

\section{Neuromuscular blockade}

Neuromuscular blockers are used in ARDS to improve patient-ventilator synchrony, to facilitate lung-protective ventilation, and to improve chest wall compliance. These blockers also reduce oxygen consumption by respiratory (and other skeletal) muscles, leading to an improved mixed venous saturation and in turn to an improved partial pressure of arterial oxygen, all other things being equal in most ARDS patients. In a recent large RCT, cisatracurium infusion for a 48-hour period early in the course of moderate-severe ARDS $\left(\mathrm{PaO}_{2} / \mathrm{FiO}_{2}\right.$ ratio 
$<150 \mathrm{mmHg}$ ) resulted in a reduction in the duration of mechanical ventilation and mortality [62]. Concerns regarding the use of neuromuscular blockers relate primarily to the risk of critical illness myopathy [63,64], a concern that was not borne out in this study and which may have been overemphasised $[65,66]$. Aminosteroid muscle relaxants such as rocuronium may present a higher risk than benzylquinolinium compounds such as cisatracurium in this regard [67]. In this group of severe ARDS patients, almost all of whom will require heavy sedation to facilitate lung-protective ventilation and patient-ventilator synchrony, some benefit of neuromuscular blockers may derive from a sedativesparing effect. Our current approach is to consider neuromuscular blockade for patients with severe ARDS in whom patient-ventilator asynchrony is thought to contribute to difficulty in gas exchange or in achieving lung-protective ventilation.

\section{Other pharmacological adjuncts}

Based on the observation that hypoproteinaemia is a strong risk factor for ARDS [68], the use of albumin along with furosemide has been studied in two small phase II trials $[69,70]$. Albumin use was associated with improved oxygenation, diuresis and haemodynamics, and represents an approach in need of further evaluation.

Corticosteroids have been investigated extensively in ARDS. High-dose steroids used in the early stages of ARDS have no benefit and may increase the rate of infectious complications $[71,72]$. One small randomised study suggested a survival benefit in the late (fibroproliferative) phase of ARDS [73], but a larger study failed to replicate this benefit despite showing improvements in physiological parameters [74]. Most recently, a trial of early, low-dose steroids in ARDS showed improvements in gas exchange without improvements in clinically significant endpoints [75]. Overall, the data are unclear and thus steroids have yet to find their place in the routine management of ARDS.

Other agents with a biological rationale but that have recently failed to demonstrate clinical utility in randomised trials include $\beta$-agonists (both nebulised and intravenous) $[76,77]$ and omega-3 fatty acid supplements [78].

\section{Nonpharmacological adjuncts}

Prone positioning has a sound pathophysiologic basis and has been used for many years in the management of ARDS. Recruitment of dorsal lung regions where greater lung mass is located, displacement of the cardiac mass away from lung tissue, and more homogeneous distribution of ventilation in the prone position are among the mechanisms postulated for the improved oxygenation that is consistently observed in studies of prone positioning in ARDS. Unfortunately, several large trials have demonstrated that although oxygenation generally improves with prone positioning, this does not appear to result in a survival benefit when all patients with ARDS are considered [79-83]. Two recent meta-analyses did, however, demonstrate an improvement in ICU mortality in patients with severe ARDS [84]. The benefit appears to be greater when the prone position is maintained for longer (that is, 17 or 18 hours), and although significant complications can develop (skin necrosis, dislodgement of catheters and tubes) these are not significantly more frequent when prone positioning is used. Prone positioning should be considered as an option to improve oxygenation for patients in whom conventional measures have failed and for patients with severe ARDS $\left(\mathrm{PaO}_{2} / \mathrm{FiO}_{2}\right.$ $<100$ ).

The injurious effects and limitations of conventional ventilation have led to the development of a number of alternative modes of ventilation. Airway pressure release ventilation is a spontaneous breathing mode in which a high baseline pressure is released to a low level intermittently (6 to 12 times/minute) to allow ventilation, with spontaneous breaths permitted throughout the cycle. This technique may result in improvements in lung recruitment, oxygenation, and patient-ventilator synchrony, although with the potential cost of alveolar overdistension. Although some early studies have been promising, no definite outcome benefit has been demonstrated to date for this mode of ventilation $[31,32,85]$.

Neurally adjusted ventilatory assist utilises an oesophageal electrode to measure diaphragmatic electrical activity, delivering positive pressure proportionately. While potentially useful in patients who are difficult to manage with conventional ventilation due to asynchrony $[86,87]$, no prospective outcome studies have been carried out in ARDS patients.

High-frequency oscillatory ventilation utilises rapidly cycling positive and negative pressure oscillations around a high mean airway pressure to deliver very small tidal volumes at high frequencies (5 to $15 \mathrm{~Hz}$ or 300 to 900 per minute). The mechanisms of gas flow and ventilation involved are complex, but high-frequency oscillatory ventilation appears to result in maintenance of lung recruitment as well as improvements in oxygenation and ventilation in ARDS patients refractory to conventional ventilation and is potentially less injurious to the lung [88]. At the current time, high-frequency oscillatory ventilation appears safe and appropriate as rescue therapy for patients with refractory hypoxemia [89]. Results are expected in the near future from at least two large clinical trials comparing high-frequency oscillatory ventilation with conventional ventilation in moderatesevere ARDS patients.

The role of extracorporeal lung support in ARDS is controversial and availability is currently limited to 
specialist centres. The most extensively studied form used in ARDS patients is venovenous extracorporeal membrane oxygenation (ECMO). A recent RCT of transfer to an ECMO centre found a mortality benefit when compared with conventional therapy [90]. However, this study has been criticised for conflating ECMO treatment and regionalisation effects, and for a lack of well-documented protective ventilation in the control group. Even more recently the H1N1 influenza epidemic has highlighted the potential benefits of extracorporeal lung support [91,92]. Potential drawbacks of extracorporeal lung support include lack of widespread availability and the need for systemic anticoagulation. Transfer to an ECMO centre should be considered in patients with reversible disease in whom lung-protective ventilation cannot provide acceptable gas exchange when other rescue measures have failed, and should be utilised early in the course of disease, before irreversible lung injury has occurred.

\section{Future directions}

There remain a large number of unanswered questions in the management of ARDS. The role of nonconventional ventilatory techniques is currently under study, as are the utility of extracorporeal carbon dioxide removal in conjunction with ultra-low tidal volume ventilation and the utility of ECMO for severe ARDS. Dependence on conventional positive-pressure ventilation may decline if these new technologies find a place.

\section{Conclusion}

Understanding mechanical ventilation as a potentially harmful yet life-saving intervention has led to the development of an approach that aims to minimise harm while providing acceptable gas exchange. Ventilation in ARDS should include the use of low tidal volumes, the avoidance of high plateau pressures, titration of PEEP to provide acceptable oxygenation, and avoidance of high inspired oxygen concentrations. Individualised targets for oxygenation and carbon dioxide clearance should be set, recognising the lack of harm associated with hypercapnia and the risk of harm associated with high inspired oxygen concentrations.

Useful rescue strategies when lung-protective ventilation fails to provide acceptable gas exchange include recruitment manoeuvres and optimisation of PEEP, neuromuscular blockade, and prone positioning. Fluid overload must be avoided, and diuretics or ultrafiltration should be used to achieve a negative fluid balance in stable patients. Failure of these measures should lead to consideration of nonconventional modes of ventilation or the use of extracorporeal therapies in selected patients with reversible disease. In spite of all these measures, however, ARDS remains a difficult clinical problem and carries a high mortality - we still have work to do [2].

\section{Abbreviations}

ARDS, acute respiratory distress syndrome; ECMO, extracorporeal membrane oxygenation; $\mathrm{FiO}_{2^{\prime}}$ fraction of inspired oxygen; $\mathrm{PaO}_{2^{\prime}}$ partial pressure of arterial oxygen; PEEP, positive end-expiratory pressure; RCT, randomised controlled trial; VILI, ventilator-induced lung injury.

\section{Acknowledgements}

NDF is supported by a New Investigator Award from the Canadian Institutes of Health Research (Ottawa, Canada).

\section{Competing interests}

The authors declare that they have no competing interests.

\section{Author details}

'Interdepartmental Division of Critical Care, University of Toronto, 600 University Avenue, Suite 18-206, Toronto, ON, Canada M5G 1X5..

${ }^{2}$ Department of Medicine, Division of Respirology, University Health Network and Mount Sinai Hospital, University of Toronto, Mount Sinai Hospital, 600 University Avenue, Suite 18-206, Toronto, ON, Canada M5G 1X5.

Published: 29 April 2012

\section{References}

1. Ashbaugh DG, Bigelow DB, Petty TL, Levine BE: Acute respiratory distress in adults. Lancet 1967, 2:319-323.

2. Phua J, Badia JR, Adhikari NKJ, Friedrich JO, Fowler RA, Singh JM, Scales DC, Stather DR, Li A, Jones A, Gattas DJ, Hallett D, Tomlinson G, Stewart TE, Ferguson ND: Has mortality from acute respiratory distress syndrome decreased over time?: a systematic review. Am J Respir Crit Care Med 2009, 179:220-227.

3. Herridge MS: Recovery and long-term outcome in acute respiratory distress syndrome. Crit Care Clin 2011, 27:685-704.

4. Villar J, Blanco J, Kacmarek RM: Acute respiratory distress syndrome definition: do we need a change? Curr Opin Crit Care 2011, 17:13-17.

5. Ferguson ND, Frutos-Vivar F, Esteban A, Fernández-Segoviano P, Aramburu JA, Nájera L, Stewart TE: Acute respiratory distress syndrome: underrecognition by clinicians and diagnostic accuracy of three clinical definitions. Crit Care Med 2005, 33:2228-2234.

6. Rumbak MJ, Solomon DA: Does the clinical consensus definition of ALI/ ARDS continue to fit our needs? Chest 2009, 135:251-252.

7. Soni N: ARDS, acronyms and the Pinocchio effect. Anaesthesia 2010, 65:976-979.

8. Bernard GR, Artigas A, Brigham KL, Carlet J, Falke K, Hudson L, Lamy M, LeGall JR, Morris A, Spragg R: The American-European Consensus Conference on ARDS. Definitions, mechanisms, relevant outcomes, and clinical trial coordination. Am J Respir Crit Care Med 1994, 149:818-824.

9. ARDS Definition Task Force: Acute respiratory distress syndrome: the Berlin Definition. JAMA 2012, 307:2526-2533.

10. Johnson ER, Matthay MA. Acute lung injury: epidemiology, pathogenesis, and treatment. J Aerosol Med Pulm Drug Deliv 2010, 23:243-252.

11. Gattinoni L, Caironi P, Pelosi P, Goodman LR: What has computed tomography taught us about the acute respiratory distress syndrome? Am J Respir Crit Care Med 2001, 164:1701-1711.

12. Gattinoni L, Pesenti A: The concept of 'baby lung'. Intensive Care Med 2005, 31:776-784.

13. Rocker GM, Mackenzie MG, Williams B, Logan PM: Noninvasive positive pressure ventilation: successful outcome in patients with acute lung injury/ARDS. Chest 1999, 115:173-177.

14. Wolthuis EK, Vlaar APJ, Choi G, Roelofs JJTH, Juffermans NP, Schultz MJ: Mechanical ventilation using non-injurious ventilation settings causes lung injury in the absence of pre-existing lung injury in healthy mice. Crit Care 2009, 13:R1

15. Plötz FB, Slutsky AS, Van Vught AJ, Heijnen CJ: Ventilator-induced lung injury and multiple system organ failure: a critical review of facts and hypotheses. Intensive Care Med 2004, 30:1865-1872.

16. Villar J, Blanco J, Zhang H, Slutsky AS. Ventilator-induced lung injury and sepsis: two sides of the same coin? Minerva Anestesiol 2011, 77:647-653.

17. Stapleton RD: Causes and timing of death in patients with ARDS. Chest 2005, 128:525-532

18. Grocott MPW, Martin DS, Levett DZH, McMorrow R, Windsor J, Montgomery $\mathrm{HE}$; Caudwell Xtreme Everest Research Group: Arterial blood gases and 
oxygen content in climbers on Mount Everest. NEngl J Med 2009, 360:140-149.

19. Lund T, Koller ME, Kofstad J: Severe hypoxemia without evidence of tissue hypoxia in adult respiratory distress syndrome. Crit Care Med 1984, 12:75-76

20. Hopkins RO, Weaver LK, Pope D, Orme JF, Bigler ED, Larson-Lohr V: Neuropsychological sequelae and impaired health status in survivors of severe acute respiratory distress syndrome. Am J Respir Crit Care Med 1999, 160:50-56.

21. Garner WL, Downs JB, Reilley TE, Frolicher D, Kargi A, Fabri PJ: The effects of hyperoxia during fulminant sepsis. Surgery 1989, 105:747-751.

22. Klein J: Normobaric pulmonary oxygen toxicity. Anesth Analg 1990, 70:195-207.

23. Caldwell PR, Lee WL, Schildkraut HS, Archibald ER: Changes in lung volume, diffusing capacity, and blood gases in men breathing oxygen. J Appl Physiol 1966, 21:1477-1483.

24. Davis WB, Rennard SI, Bitterman PB, Crystal RG: Pulmonary oxygen toxicity. Early reversible changes in human alveolar structures induced by hyperoxia. N Engl J Med 1983, 309:878-883.

25. Santos C, Ferrer M, Roca J, Torres A, Hernández C, Rodriguez-Roisin R: Pulmonary gas exchange response to oxygen breathing in acute lung injury. Am J Respir Crit Care Med 2000, 161:26-31.

26. Acute Respiratory Distress Syndrome Network: Ventilation with lower tidal volumes as compared with traditional tidal volumes for acute lung injury and the acute respiratory distress syndrome. N Eng/ J Med 2000, 342:1301-1308.

27. Ijland MM, Heunks LM, van der Hoeven JG: Bench-to-bedside review: hypercapnic acidosis in lung injury - from 'permissive' to 'therapeutic'. Crit Care 2010, 14:237.

28. Thorens JB, Jolliet P, Ritz M, Chevrolet JC: Effects of rapid permissive hypercapnia on hemodynamics, gas exchange, and oxygen transport and consumption during mechanical ventilation for the acute respiratory distress syndrome. Intensive Care Med 1996, 22:182-191

29. Hickling $K G$, Walsh J, Henderson S, Jackson R: Low mortality rate in adult respiratory distress syndrome using low-volume, pressure-limited ventilation with permissive hypercapnia: a prospective study. Crit Care Med 1994, 22:1568-1578

30. McMullen SM, Meade M, Rose L, Burns K, Mehta S, Doyle R, Henzler D; Canadian Critical Care Trials Group: Partial ventilatory support modalities in acute lung injury and acute respiratory distress syndrome - a systematic review. PLOS ONE 2012, 7:e40190.

31. Putensen $C$, Zech S, Wrigge H, Zinserling J, Stüber F, Spiegel Von T, Mutz N: Long-term effects of spontaneous breathing during ventilatory support in patients with acute lung injury. Am J Respir Crit Care Med 2001, 164:43-49.

32. Varpula T, Valta P, Niemi R, Takkunen O, Hynynen M, Pettilä W: Airway pressure release ventilation as a primary ventilatory mode in acute respiratory distress syndrome. Acta Anaesthesiol Scand 2004, 48:722-731.

33. Marini JJ: Point: is pressure assist-control preferred over volume assistcontrol mode for lung protective ventilation in patients with ARDS? Yes. Chest 2011, 140:286-290.

34. Maclntyre N: Counterpoint: Is pressure assist-control preferred over volume assist-control mode for lung protective ventilation in patients with ARDS? No. Chest 2011, 140:290-292.

35. Toth I, Leiner T, Mikor A, Szakmany T, Bogar L, Molnar Z: Hemodynamic and respiratory changes during lung recruitment and descending optimal positive end-expiratory pressure titration in patients with acute respiratory distress syndrome. Crit Care Med 2007, 35:787-793.

36. Hodgson CL, Tuxen DV, Davies AR, Bailey MJ, Higgins AM, Holland AE, Keating $J L$, Pilcher DV, Westbrook AJ, Cooper DJ, Nichol AD: A randomised controlled trial of an open lung strategy with staircase recruitment, titrated PEEP and targeted low airway pressures in patients with acute respiratory distress syndrome. Crit Care 2011, 15:R133.

37. Borges JB, Okamoto VN, Matos GFJ, Caramez MPR, Arantes PR, Barros F, Souza CE, Victorino JA, Kacmarek RM, Barbas CSV, Carvalho CRR, Amato MBP. Reversibility of lung collapse and hypoxemia in early acute respiratory distress syndrome. Am J Respir Crit Care Med 2006, 174:268-278.

38. Hodgson C, Keating JL, Holland AE, Davies AR, Smirneos L, Bradley SJ, Tuxen $D$ : Recruitment manoeuvres for adults with acute lung injury receiving mechanical ventilation. Cochrane Database Syst Rev 2009, 2:CD006667.

39. Fan E, Wilcox ME, Brower RG, Stewart TE, Mehta S, Lapinsky SE, Meade MO, Ferguson ND: Recruitment maneuvers for acute lung injury: a systematic review. Am J Respir Crit Care Med 2008, 178:1156-1163.

40. Ferguson ND, Frutos-Vivar F, Esteban A, Anzueto A, Alía I, Brower RG, Stewart TE, Apezteguía C, González M, Soto L, Abroug F, Brochard L; Mechanical Ventilation International Study Group: Airway pressures, tidal volumes, and mortality in patients with acute respiratory distress syndrome. Crit Care Med 2005, 33:21-30.

41. Brower RG, Lanken PN, Maclntyre N, Matthay MA, Morris A, Ancukiewicz M, Schoenfeld D, Thompson BT; National Heart Lung and Blood Institute ARDS Clinical Trials Network: Higher versus lower positive end-expiratory pressures in patients with the acute respiratory distress syndrome. N Eng/J Med 2004, 351:327-336.

42. Meade MO, Cook DJ, Guyatt GH, Slutsky AS, Arabi YM, Cooper DJ, Davies AR, Hand LE, Zhou Q, Thabane L, Austin P, Lapinsky S, Baxter A, Russell J, Skrobik Y, Ronco JJ, Stewart TE; Lung Open Ventilation Study Investigators: Ventilation strategy using low tidal volumes, recruitment maneuvers, and high positive end-expiratory pressure for acute lung injury and acute respiratory distress syndrome: a randomized controlled trial. JAMA 2008, 299:637-645

43. Mercat A, Richard J-CM, Vielle B, Jaber S, Osman D, Diehl J-L, Lefrant J-Y, Prat G, Richecoeur J, Nieszkowska A, Gervais C, Baudot J, Bouadma L, Brochard L; Expiratory Pressure Express Study Group: Positive end-expiratory pressure setting in adults with acute lung injury and acute respiratory distress syndrome: a randomized controlled trial. JAMA 2008, 299:646-655.

44. Briel M, Meade M, Mercat A, Brower RG, Talmor D, Walter SD, Slutsky AS, Pullenayegum E, Zhou Q, Cook D, Brochard L, Richard J-CM, Lamontagne F, Bhatnagar N, Stewart TE, Guyatt G: Higher vs lower positive end-expiratory pressure in patients with acute lung injury and acute respiratory distress syndrome: systematic review and meta-analysis. JAMA 2010, 303:865-873.

45. Suarez-Sipmann F, Böhm SH: Recruit the lung before titrating the right positive end-expiratory pressure to protect it. Crit Care 2009, 13:134.

46. Suarez-Sipmann F, Böhm SH, Tusman G, Pesch T, Thamm O, Reissmann H, Reske A, Magnusson A, Hedenstierna G: Use of dynamic compliance for open lung positive end-expiratory pressure titration in an experimental study. Crit Care Med 2007, 35:214-221.

47. Caramez MP, Kacmarek RM, Helmy M, Miyoshi E, Malhotra A, Amato MBP, Harris RS: A comparison of methods to identify open-lung PEEP. Intensive Care Med 2009, 35:740-747.

48. Talmor D, Sarge T, Malhotra A, O'Donnell CR, Ritz R, Lisbon A, Novack V, Loring $\mathrm{SH}$ : Mechanical ventilation guided by esophageal pressure in acute lung injury. N Engl J Med 2008, 359:2095-2104.

49. Liu S-Q, Chen J, Huang Y-Z, Guo F-M, Liu L, Yang Y: [Dead space guided positive end-expiratory pressure in patients with acute respiratory distress syndrome]. Zhonghua Nei Ke Za Zhi 2011, 50:926-930.

50. Tremper KK, Waxman K, Shoemaker WC: Use of transcutaneous oxygen sensors to titrate PEEP. Ann Surg 1981, 193:206-209.

51. Huang CC, Shih MJ, Tsai YH, Chang YC, Tsao TC, Hsu KH: Effects of inverse ratio ventilation versus positive end-expiratory pressure on gas exchange and gastric intramucosal $\mathrm{PCO}_{2}$ and $\mathrm{pH}$ under constant mean airway pressure in acute respiratory distress syndrome. Anesthesiology 2001, 95:1182-1188

52. Mercat A, Titiriga M, Anguel N, Richard C, Teboul JL: Inverse ratio ventilation $(\mathrm{I} / \mathrm{E}=2 / 1)$ in acute respiratory distress syndrome: a six-hour controlled study. Am J Respir Crit Care Med 1997, 155:1637-1642.

53. Adhikari NKJ, Burns KEA, Friedrich JO, Granton JT, Cook DJ, Meade MO Effect of nitric oxide on oxygenation and mortality in acute lung injury: systematic review and meta-analysis. BMJ 2007, 334:779.

54. Afshari A, Brok J, Møller AM, Wetterslev J: Inhaled nitric oxide for acute respiratory distress syndrome (ARDS) and acute lung injury in children and adults. Cochrane Database Syst Rev 2010, 7:CD002787.

55. van Heerden PV, Barden A, Michalopoulos N, Bulsara MK, Roberts BL: Dose-response to inhaled aerosolized prostacyclin for hypoxemia due to ARDS. Chest 2000, 117:819-827.

56. Zwissler B, Kemming G, Habler O, Kleen M, Merkel M, Haller M, Briegel J, Welte $M$, Peter K: Inhaled prostacyclin (PGI2) versus inhaled nitric oxide in adult respiratory distress syndrome. Am J Respir Crit Care Med 1996, 154:1671-1677.

57. Sakr Y, Vincent J-L, Reinhart K, Groeneveld J, Michalopoulos A, Sprung CL, Artigas A, Ranieri VM; Sepsis Occurrence in Acutely III Patients I: High tidal volume and positive fluid balance are associated with worse outcome in acute lung injury. Chest 2005, 128:3098-3108.

58. Grams ME, Estrella MM, Coresh J, Brower RG, Liu KD; National Heart, Lung, and 
Blood Institute Acute Respiratory Distress Syndrome Network: Fluid balance, diuretic use, and mortality in acute kidney injury. Clin J Am Soc Nephrol 2011, 6:966-973

59. National Heart Lung and Blood Institute Acute Respiratory Distress Syndrome ARDS Clinical Trials Network; Wiedemann HP, Wheeler AP, Bernard GR, Thompson BT, Hayden D, deBoisblanc B, Connors AF, Hite RD, Harabin AL: Comparison of two fluid-management strategies in acute lung injury. N Engl J Med 2006, 354:2564-2575.

60. Liu KD, Thompson BT, Ancukiewicz M, Steingrub JS, Douglas IS, Matthay MA Wright P, Peterson MW, Rock P, Hyzy RC, Anzueto A, Truwit JD; National Institutes of Health National Heart, Lung and Blood Institute Acute Respiratory Distress Syndrome Network: Acute kidney injury in patients with acute lung injury: impact of fluid accumulation on classification of acute kidney injury and associated outcomes. Crit Care Med 2011, 39:2665-2671.

61. Mikkelsen ME, Christie JD, Lanken PN, Biester RC, Thompson BT, Bellamy SL, Localio AR, Demissie E, Hopkins RO, Angus DC: The adult respiratory distress syndrome cognitive outcomes study: long-term neuropsychological function in survivors of acute lung injury. Am J Respir Crit Care Med 2012, 185:1307-1315.

62. Papazian L, Forel J-M, Gacouin A, Penot-Ragon C, Perrin G, Loundou A, Jaber S, Arnal J-M, Perez D, Seghboyan J-M, Constantin J-M, Courant P, Lefrant J-Y, Guérin C, Prat G, Morange S, Roch A; ACURASYS Study Investigators: Neuromuscular blockers in early acute respiratory distress syndrome. N Engl J Med 2010, 363:1107-1116.

63. Leatherman JW, Fluegel WL, David WS, Davies SF, Iber C: Muscle weakness in mechanically ventilated patients with severe asthma. Am J Respir Crit Care Med 1996, 153:1686-1690.

64. Adnet F, Dhissi G, Borron SW, Galinski M, Rayeh F, Cupa M, Pourriat JL, Lapostolle F: Complication profiles of adult asthmatics requiring paralysis during mechanical ventilation. Intensive Care Med 2001, 27:1729-1736.

65. Weber-Carstens S, Deja M, Koch S, Spranger J, Bubser F, Wernecke KD, Spies CD, Spuler S, Keh D: Risk factors in critical illness myopathy during the early course of critical illness: a prospective observational study. Crit Care 2010, 14:R119.

66. De Jonghe B, Sharshar T, Lefaucheur JP, Authier FJ, Durand-Zaleski I, Boussarsar M, Cerf C, Renaud E, Mesrati F, Carlet J, Raphael JC, Outin H, Bastuji-Garin S: Paresis acquired in the intensive care unit: a prospective multicenter study. JAMA 2002, 288:2859-2867.

67. Testelmans D, Maes K, Wouters P, Gosselin N, Deruisseau K, Powers S, Sciot R, Decramer M, Gayan-Ramirez G: Rocuronium exacerbates mechanical ventilation-induced diaphragm dysfunction in rats. Crit Care Med 2006, 34:3018-3023

68. Mangialardi RJ, Martin GS, Bernard GR, Wheeler AP, Christman BW, Dupont WD, Higgins SB, Swindell BB: Hypoproteinemia predicts acute respiratory distress syndrome development, weight gain, and death in patients with sepsis. Ibuprofen in Sepsis Study Group. Crit Care Med 2000, 28:3137-3145.

69. Martin GS, Moss M, Wheeler AP, Mealer M, Morris JA, Bernard GR: A randomized, controlled trial of furosemide with or without albumin in hypoproteinemic patients with acute lung injury. Crit Care Med 2005, 33:1681-1687.

70. Martin GS, Mangialardi RJ, Wheeler AP, Dupont WD, Morris JA, Bernard GR: Albumin and furosemide therapy in hypoproteinemic patients with acute lung injury. Crit Care Med 2002, 30:2175-2182.

71. Weigelt JA, Norcross JF, Borman KR, Snyder WH: Early steroid therapy for respiratory failure. Arch Surg 1985, 120:536-540.

72. Bernard GR, Luce JM, Sprung CL, Rinaldo JE, Tate RM, Sibbald WJ, Kariman K, Higgins S, Bradley R, Metz CA: High-dose corticosteroids in patients with the adult respiratory distress syndrome. N Eng/ J Med 1987, 317:1565-1570

73. Meduri GU, Headley AS, Golden E, Carson SJ, Umberger RA, Kelso T, Tolley EA: Effect of prolonged methylprednisolone therapy in unresolving acute respiratory distress syndrome: a randomized controlled trial. JAMA 1998, 280:159-165.

74. Steinberg KP, Hudson LD, Goodman RB, Hough CL, Lanken PN, Hyzy R, Thompson BT, Ancukiewicz M; National Heart Lung and Blood Institute Acute Respiratory Distress Syndrome ARDS Clinical Trials Network: Efficacy and safety of corticosteroids for persistent acute respiratory distress syndrome. N Engl J Med 2006, 354:1671-1684.

75. Meduri GU, Golden E, Freire AX, Taylor E, Zaman M, Carson SJ, Gibson M, Umberger R: Methylprednisolone infusion in early severe ARDS: results of a randomized controlled trial. Chest 2007, 131:954-963.
76. National Heart, Lung, and Blood Institute Acute Respiratory Distress Syndrome Clinical Trials Network: Randomized, placebo-controlled clinical trial of an aerosolized 2-agonist for treatment of acute lung injury. Am J Respir Crit Care Med 2011, 184:561-568.

77. Gao Smith F, Perkins GD, Gates S, Young D, McAuley DF, Tunnicliffe W, Khan Z, Lamb SE; BALTI-2 study investigators: Effect of intravenous $\beta-2$ agonist treatment on clinical outcomes in acute respiratory distress syndrome (BALTI-2): a multicentre, randomised controlled trial. Lancet 2012, 379:229-235

78. Rice TW, Wheeler AP, Thompson BT, Deboisblanc BP, Steingrub J, Rock P; NHLBI ARDS Clinical Trials Network: Enteral omega-3 fatty acid, $\gamma$-linolenic acid, and antioxidant supplementation in acute lung injury. JAMA 2011, 306:1574-1581.

79. Taccone P, Pesenti A, Latini R, Polli F, Vagginelli F, Mietto C, Caspani L, Raimondi F, Bordone G, lapichino G, Mancebo J, Guérin C, Ayzac L, Blanch L, Fumagalli R, Tognoni G, Gattinoni L; Prone-Supine II Study Group: Prone positioning in patients with moderate and severe acute respiratory distress syndrome: a randomized controlled trial. JAMA 2009, 302:1977-1984.

80. Fernández R, Trenchs X, Klamburg J, Castedo J, Serrano JM, Besso G, Tirapu JP, Santos A, Mas A, Parraga M, Jubert P, Frutos F, Añón JM, Garcia M, Rodriguez F, Yebenes JC, Lopez MJ: Prone positioning in acute respiratory distress syndrome: a multicenter randomized clinical trial. Intensive Care Med 2008, 34:1487-1491.

81. Gattinoni L, Tognoni G, Pesenti A, Taccone P, Mascheroni D, Labarta V, Malacrida R, Di Giulio P, Fumagalli R, Pelosi P, Brazzi L, Latini R; Prone-Supine Study Group: Effect of prone positioning on the survival of patients with acute respiratory failure. N Engl J Med 2001, 345:568-573.

82. Mancebo J, Fernandez R, Blanch L, Rialp G, Gordo F, Ferrer M, Rodríguez F, Garro P, Ricart P, Vallverdú I,Gich I, Castaño J, Saura P, Domínguez G, Bonet A, Albert RK: A multicenter trial of prolonged prone ventilation in severe acute respiratory distress syndrome. Am J Respir Crit Care Med 2006, 173:1233-1239.

83. Charron C, Bouferrache K, Caille V, Castro S, Aegerter P, Page B, Jardin F, Vieillard-Baron A: Routine prone positioning in patients with severe ARDS: feasibility and impact on prognosis. Intensive Care Med 2011, 37:785-790.

84. Sud S, Friedrich JO, Taccone P, Polli F, Adhikari NKJ, Latini R, Pesenti A, Guerin C, Mancebo J, Curley MAQ, Fernández R, Chan M-C, Beuret P, Voggenreiter G, Sud M, Tognoni G, Gattinoni L: Prone ventilation reduces mortality in patients with acute respiratory failure and severe hypoxemia: systematic review and meta-analysis. Intensive Care Med 2010, 36:585-599.

85. González M, Arroliga AC, Frutos-Vivar F, Raymondos K, Esteban A, Putensen C, Apezteguía C, Hurtado J, Desmery P, Tomicic V, Elizalde J, Abroug F, Arabi Y, Moreno R, Anzueto A, Ferguson ND: Airway pressure release ventilation versus assist-control ventilation: a comparative propensity score and international cohort study. Intensive Care Med 2010, 36:817-827.

86. Piquilloud L, Vignaux L, Bialais E, Roeseler J, Sottiaux T, Laterre P-F, Jolliet P, Tassaux D: Neurally adjusted ventilatory assist improves patient-ventilator interaction. Intensive Care Med 2011, 37:263-271.

87. Coisel Y, Chanques G, Jung B, Constantin J-M, Capdevila X, Matecki S, Grasso $S$, Jaber S: Neurally adjusted ventilatory assist in critically ill postoperative patients: a crossover randomized study. Anesthesiology 2010, 113:925-935.

88. Chan KPW, Stewart TE, Mehta S: High-frequency oscillatory ventilation for adult patients with ARDS. Chest 2007, 131:1907-1916.

89. Ali S, Ferguson ND: High-frequency oscillatory ventilation in ALI/ARDS. Crit Care Clin 2011, 27:487-499.

90. Peek GJ, Mugford M, Tiruvoipati R, Wilson A, Allen E, Thalanany MM, Hibbert CL, Truesdale A, Clemens F, Cooper N, Firmin RK, Elbourne D; CESAR Trial Collaboration: Efficacy and economic assessment of conventional ventilatory support versus extracorporeal membrane oxygenation for severe adult respiratory failure (CESAR): a multicentre randomised controlled trial. Lancet 2009, 374:1351-1363.

91. Noah MA, Peek GJ, Finney SJ, Griffiths MJ, Harrison DA, Grieve R, Sadique MZ, Sekhon JS, McAuley DF, Firmin RK, Harvey C, Cordingley JJ, Price S, Vuylsteke A, Jenkins DP, Noble DW, Bloomfield R, Walsh TS, Perkins GD, Menon D, Taylor BL, Rowan KM: Referral to an extracorporeal membrane oxygenation center and mortality among patients with severe 2009 influenza $A(H 1 N 1)$. JAMA 2011, 306:1659-1668.

92. Australia and New Zealand Extracorporeal Membrane Oxygenation Influenza Investigators; Davies A, Jones D, Bailey M, Beca J, Bellomo R, Blackwell N, Forrest P, Gattas D, Granger E, Herkes R,Jackson A, McGuinness S, Nair P, 
Pellegrino V, Pettilä V, Plunkett B, Pye R, Torzillo P, Webb S, Wilson M,Ziegenfuss M: Extracorporeal membrane oxygenation for 2009 influenza A(H1N1) acute respiratory distress syndrome. JAMA 2009, 302:1888-1895. doi:10.1186/cc11867

Cite this article as: Silversides JA, Ferguson ND: Clinical review: Acute respiratory distress syndrome - clinical ventilator management and adjunct therapy. Critical Care 2013, 17:225. 
In-hospital time to death
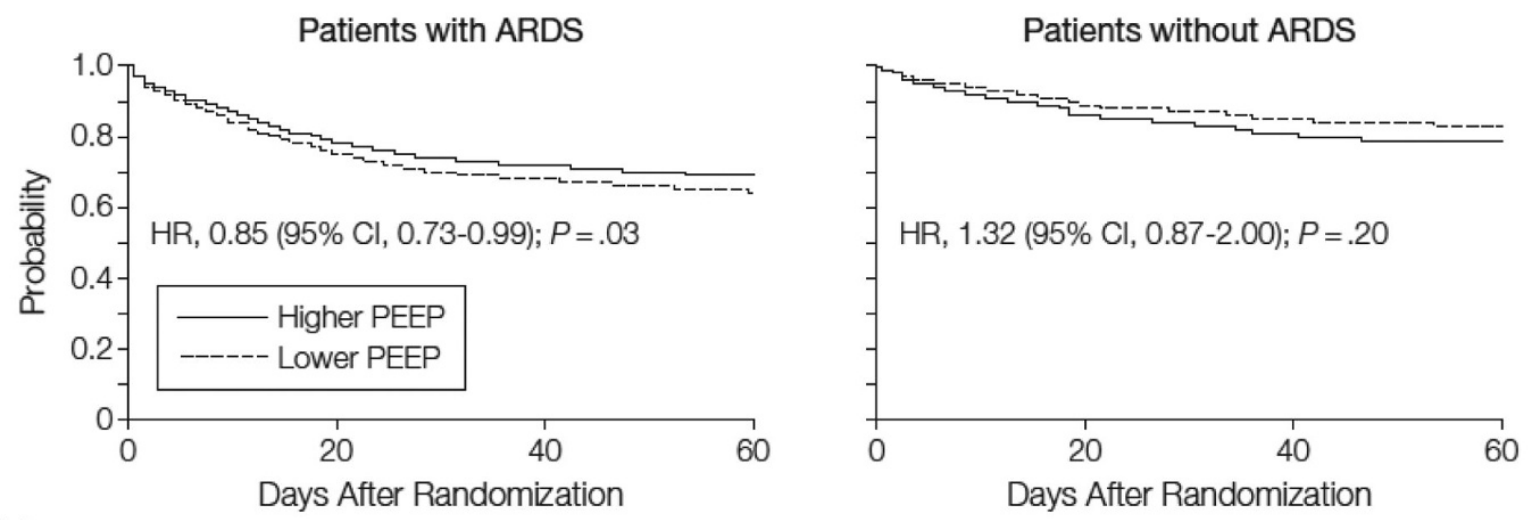

No. at risk

Higher PEEP 949

760

693

666

723

649

619

183

219

158

196 